\title{
"ISTI NON CHRISTIANI, SED PAGANI SUNT»: PERVIVENCIAS PAGANAS Y CRÍTICAS ECLESIÁSTICAS EN HISPANIA DURANTE LA ANTIGÜEDAD TARDÍA*
}

\author{
POR \\ JUAN ANTONIO JIMÉNEZ SÁNCHEZ ${ }^{1}$ \\ Universidad de Barcelona
}

\section{RESUMEN}

En el presente trabajo, analizamos algunos de los principales testimonios concernientes a la idolatría en Hispania entre los siglos IV y VII para comprobar cuánto de los rituales paganizantes pertenecía a la esfera del culto y cuánto al espectro de lo meramente folclórico. Asimismo, nos interesa sobremanera captar la visión del eclesiástico, quien, independientemente de la verdadera naturaleza de estas manifestaciones, las interpretó siempre en clave politeísta. En efecto, fueran o no un fenómeno cultual, tales expresiones de la religiosidad popular resultaban del todo ajenas a la fe de Cristo, por lo que para las autoridades religiosas constituían el fruto de los engaños de Satán y de sus ángeles y, por tanto, eran siempre condenables.

PALABRAS CLAVE: paganismo; religiosidad popular; críticas eclesiásticas; Hispania; Antigüedad tardía.

\section{"ISTI NON CHRISTIANI, SED PAGANI SUNT": PAGAN SURVIVALS AND ECCLESIASTICAL CRITICISM IN HISPANIA DURING LATE ANTIQUITY}

\begin{abstract}
In the present work we analyze some of the main testimonies concerning idolatry in Hispania between the 4th and 7th centuries in order to verify how much of the pagan rituals belonged to the sphere of the worship and how much to the spectrum of the merely folkloric. Likewise, we are deeply interested in understanding the vision of the churchman, who, regardless of the true nature of these manifestations, always interpreted them in a polytheistic way. In fact, whether or not they were a cult phenomenon, such expressions of popular religiosity were totally alien to the faith of Christ, so for the religious authorities they were the result of the deceptions of Satan and his angels and, therefore, they were always reprehensible.
\end{abstract}

KEY WORDS: paganism; popular religiosity; ecclesiastical criticism; Hispania; Late Antiquity.

Cómo CITAR ESTE ARTículo / CiTATION: Jiménez Sánchez, Juan Antonio. 2021. " "Isti non christiani, sed pagani sunt": pervivencias paganas y críticas eclesiásticas en Hispania durante la Antigüedad tardía». Hispania Sacra LXXIII, 147: 77-87. https://doi. org/10.3989/hs.2021.007

Recibido/Received 21-02-2019

Aceptado/Accepted 27-09-2019

Isti non christiani, sed pagani sunt es una sentencia que, con algunas variaciones, se repite periódicamente, como un verdadero leitmotiv, en la Homilia de sacrilegiis, un sermón

Este estudio se enmarca en los proyectos de investigación HAR2016-74981-P del Ministerio de Economía y Competitividad, cuyos investigadores principales son los profesores Josep Vilella y Juan Antonio Jiménez, y del GRAT (Grup de Recerques en Antiguitat Tardana), Grup de Recerca 2017SGR-211, de la Direcció General de Recerca de la Generalitat de Catalunya, dirigido por el profesor Josep Vilella.

jjimenez@ub.edu /

ORCID iD: https://orcid.org/0000-0002-7382-1278 anónimo franco del siglo VIII. En él, el predicador reprochaba a sus oyentes que, pese a haber abrazado la fe de Cristo, se entregasen sin reparos a la práctica de toda una serie de rituales que hundían sus raíces en el más antiguo paganismo. ${ }^{2} \mathrm{El}$ autor reprodujo en su discurso, a veces ad litteram,

2 A modo de ejemplo, podemos citar Hom. de sacril., 17 [p. 10]: quicumque [in] defeccionem lunae, quando scuriscere solet, per clamorem populi uasa lignea et erea amentea battent, ahb strias depositam ipsa luna reuocare in caelum credent[es], uel qui grandinem per laminas plumbeas scriptas et per cornus incantatos auertere potant, isti non christiani, sed pagani sunt. 
muchos pasajes de obras anteriores, en especial de sermones de Cesáreo de Arlés y del De correctione rusticorum de Martín de Braga. Esto no constituía un mero ejercicio de retórica, sino que reflejaba la perpetuación de un grave problema para las autoridades eclesiásticas: la pervivencia de una serie de costumbres paganizantes en un mundo que, al menos nominalmente, había devenido cristiano desde hacía ya mucho tiempo.

El debate historiográfico generado en torno a esta cuestión, lejos de apagarse, se ha mantenido muy vivo en las últimas décadas. No es nuestra intención realizar aquí un repaso de todos los autores que se han ocupado del tema, pero sí que recordaremos que las posturas han evolucionado desde un posicionamiento que otorgaba una gran vitalidad a la idolatría en territorios como Hispania o la Galia durante los últimos años del Imperio romano de Occidente y los siguientes reinos germánicos, ${ }^{3}$ hasta otro negacionista que rechazaba la existencia de prácticas paganas en los territorios mencionados ya a partir del siglo VI. ${ }^{4}$

En el fondo, todo se reduce a una cuestión semántica: ¿qué entendemos -o mejor cabría decir «qué entendían durante la Antigüedad tardía»- por paganismo? Evidentemente, si lo identificamos tan solo con el conjunto de cultos cívicos del mundo grecorromano - es decir, con unos rituales reglamentados, bien organizados y llevados a cabo de manera oficial por unos sacerdotes mantenidos por el Estado-, habremos de reconocer que el paganismo tuvo una muerte temprana, a finales del siglo IV con la legislación antipagana promulgada por Teodosio I; con mucho, en algunos territorios del Mediterráneo se mantuvo durante el siglo $\mathrm{V}$ debido a la desidia de las autoridades locales, lo que motivó las lógicas protestas de las jerarquías eclesiásticas. ${ }^{5}$

\footnotetext{
3 McKenna 1938 sería un buen ejemplo de esta corriente de pensamiento.

4 Hen 1995 es un exponente de este pensamiento para la Galia merovingia. El ejemplo extremo lo supondría Alan Cameron (2011), cuyo exagerado hipercriticismo le ha llevado a sostener que el paganismo (entendido como el conjunto de cultos cívicos del mundo grecorromano) desapareció en Roma entre finales del siglo IV e inicios del V. De este modo, afirma: «Roman paganism was not extinguished on the field of battle [en alusión a la batalla del Frígido (394)] or even by imperial laws [en referencia, sobre todo, a las leyes teodosianas]. It died a natural death, and was already mortally ill before Theodosius embarked on his final campaign» (Cameron 2011, 131); "if we define paganism as the civic cults of the pre-Christian Graeco-Roman world, official Roman paganism really did effectively end with the disappearance of the priestly colleges in the early fifth century» (ibíd., 783). E hipercriticismo de Cameron ha sido respondido en buena parte por los diversos artículos que componen el volumen de Lizzi Testa 2013.

5 Un buen ejemplo puede leerse en la biografía de Porfirio de Gaza, donde vemos cómo este obispo envió a su diácono Marco a Constantinopla para solicitar al emperador que fueran destruidos los templos de los ídolos que se mantenían en esta ciudad, en especial el consagrado al dios Marnas. La embajada fue bien acogida gracias a Juan Crisóstomo, a la sazón obispo de Constantinopla, con lo que al cabo de una semana se expidió la carta imperial con la orden para que los templos de Gaza fueran cerrados. Un oficial de la corte fue e encargado personal de que la disposición fuera llevada a cabo. Los magistrados principales de la ciudad fueron arrestados y, tras el pago de la fianza, se les notificó el cierre de los templos bajo amenaza de muerte si permitían que continuaran abiertos. Se procedió en este modo, y los edificios de culto fueron clausurados y sus ídolos destruidos. Sin embargo, el oficial, tras ser sobornado, consintió en que el santuario de Marnas siguiera en funcionamiento; Marcus Diac., Vit. Porph. Gaz.,
} 26-27 [p. 22-24].
Siguiendo esta corriente interpretativa, ya desde los últimos años del siglo XX se ha tratado de diferenciar entre cultura y religión; es decir, entre costumbres y creencias, relegando así las costumbres al terreno de lo profano. Tal consideración ha llevado a considerar como paganismo y pervivencias paganas únicamente el culto otorgado a las deidades del politeísmo, lo cual, a su vez, ha conducido a excluir de esta categoría todos aquellos hábitos de la vida cotidiana que no contenían en sí mismos un sentido religioso o cultual; es decir, los más propiamente culturales. ${ }^{6}$

Sin embargo, si estimamos como "paganismo» todas aquellas manifestaciones religiosas ajenas al cristianismo y al judaísmo -independientemente de si en su origen se hallaban los cultos grecorromanos o los indígenas-, definición que en nuestra opinión sería la más acertada, observamos que el panorama cambia sustancialmente y el abanico de posibilidades a las que se enfrenta el estudioso se amplía de manera considerable. Hemos de tener presente que en el mundo antiguo la religión impregnaba todos los ámbitos de la vida, por lo que la distinción entre "sagrado» y "profano» que muchos buscan fijar hoy corresponde en realidad a un debate moderno: al intentar diferenciar y establecer unos límites dentro de esa dicotomía - es decir, entre lo que es religioso y lo que no lo es-, estamos imponiendo nuestros propios criterios, a una distancia de un milenio y medio del momento que estamos estudiando, con lo que nuestras conclusiones resultan sesgadas y adolecen de un cierto grado de presentismo. ${ }^{7}$ De este modo, vemos que, aunque descartemos los cultos llevados a cabo por oficiantes profesionales, aún quedaban durante la Antigüedad tardía las expresiones más o menos espontáneas de la religiosidad popular, muchas veces ligadas a cultos indígenas que se resistían a morir, realizadas de manera individual por personas que todavía se consideraban en su fuero más interno seguidoras de alguna divinidad; asimismo, numerosos individuos, en teoría cristianos, seguían perpetuando bastantes comportamientos heredados de sus ancestros que se remontaban a rituales indudablemente de tipo pagano. ${ }^{8} \mathrm{Y}$ esto era lo que más enervaba a las autoridades eclesiásticas. Por mucho que queramos insistir hoy en que tales hábitos no implicaban de facto un verdadero acto de idolatría, pues no sería esa la intención de sus practicantes, esta no era la opinión que tenían los predicadores de los siglos de transición entre el mundo antiguo y el medieval. Ellos contemplaron en todos estos comportamientos actitudes por com-

6 Markus 1990, 9-16; Díaz y Torres 2000, 236; Cameron 2011, 788. Este último autor, al negar la existencia del paganismo como una entidad en sí misma, llega a sugerir que «we should stop talking about its persistence and focus instead on the limits of the Christianisation» (Cameron 2011, 789).

Markus 1990, 8, ha puesto el acento en la dificultad de establecer dichos límites y por quién: «but how are these boundaries set, and by whom? It is evident that there two very different answers to this question, and there is an absolute necessity to distinguish them clearly. The boundaries may be drawn by us, twentieth century historians, anthropologists, theologians; or, alternatively, they may be drawn by fourth-, fifth- or sixth-century bishops, clergy, lay people. This seems an obvious enough distinction; but a long tradition of scholarship seems oblivious to it».

8 Como acertadamente apunta Brown 1995, 23, "the Church may have defeated the gods; but it had not defeated, in its own congregations, the towering force of religious habits taken directly from the non-Christian past». 
pleto ajenas a la fe de Cristo y, en consecuencia, del todo condenables $-\mathrm{y}$, además, de paso podemos preguntarnos, ¿cómo sabemos cuáles eran las verdaderas intenciones de los practicantes, cuando ellos no dejaron nada escrito y todo lo que sabemos sobre sus actividades es a través de las palabras acusadoras de los predicadores?.$-{ }^{9}$ Igualmente, conviene recordar que estos jamás estuvieron interesados en diferenciar el paganismo autóctono del grecorromano; sin importar del tipo que fuera, ellos otorgaron títulos latinos a todos los númenes, como fruto de una educación impregnada de clasicismo. En el fondo, tampoco les preocupaba excesivamente su origen, pues consideraban que Satán y sus demonios se escondían detrás de todas ellas y, por tanto, todas eran condenables por igual. ${ }^{10}$

En el caso de Hispania, el panorama que nos encontramos durante el siglo IV resulta todavía muy complejo, ${ }^{11}$ dado que a finales de esa centuria documentamos una idolatría que legalmente acaba de ser prohibida así como la presencia de cristianos entregados a determinadas manifestaciones del culto idolátrico. ${ }^{12}$

Para el estudio de la prohibición de los sacrificios en Hispania, contamos con una interesante ley recogida en el Codex Theodosianus y que fue enviada a la península ibérica a finales del siglo IV. Fue promulgada por Honorio el 29 de enero del 399 y dirigida a Macrobio, vicario de Hispania, y a Procliano, ${ }^{13}$ vicario de las Cinco Provincias (Quinque Prouinciae). ${ }^{14} \mathrm{El}$ emperador recordaba en la primera parte de esta disposición que los sacrificios estaban prohibidos, pero que por otro lado debían mantenerse incólumes los ornamentos de los monumentos públicos, los cuales, en este contexto, no pueden ser otros edificios que los templos. Añadía además el soberano que ningún individuo tendría derecho a destruir tales obras amparándose en rescripto o ley alguna. ${ }^{15}$

Este texto se ha prestado a diversas interpretaciones. Algunos autores estimaron que la preservación de los santua-

9 Sanz 2003, 11, recuerda cómo el cristianismo, al controlar la producción intelectual, relegó al paganismo «a un mundo cultural pobre, marginal, de tradición oral y ágrafo».

10 Brown 1997, 34, señala cómo los cristianos no negaron la realidad de los dioses, aunque no los consideraron como tales, sino como demonios, seres malévolos que se sirvieron de la idolatría para apartar a la gente del culto del verdadero Dios. Véase asimismo Sanz 2003, 17

11 Por razones de falta de espacio, no tenemos en cuenta en este estudio a magos y adivinos. Aunque en ambos casos algunos de estos individuos podían profesar el cristianismo -en efecto, tanto la magia como la adivinación de carácter cristiano están perfectamente documentadas para esta época-, en su mayor parte se trataba de paganos, hasta el punto de que Sanz 2003, 70, afirma: «si se me exigiera porcentualizar los restos de paganismo en la Hispania tardoantigua, sin lugar a dudas ganarían la adivinación y la magia». Acerca de este tema, véase: Sanz 1998; 2003, 70-95; Jiménez 2013; 2015.

12 La bibliografía sobre este tema resulta ingente. Aparte de los estudios mencionados en notas anteriores, podemos destacar los siguientes trabajos: Menéndez Pelayo 1880, 218-264; Arce 1971, 2006; Martínez 1972; Hillgarth 1980; Blázquez 1985; Crespo 2004; Jiménez 2005; Sanz 1995, 2007.

13 Acerca de estos individuos, véase PLRE, II, p. 698, Macrobius 1; ibid., 914, Proclianus.

14 Se trata de la diócesis de Vienne, que comprendía las provincias de Nouempopuli, Aquitanica, Narbonensis, Viennensis y Alpes Maritimiae. Tras la subdivisión de Aquitanica y Narbonensis pasó a ser conocida como "Siete Provincias» aunque en ocasiones mantuvo su antiguo nombre.

15 Cod. Theod., XVI, 10, 15 [p. 901-902]. rios en Hispania se debía a que en este territorio aún había muchos paganos que podrían sentirse ofendidos si se llevaba a cabo la demolición de sus antiguos centros cultuales, con lo que en principio esta medida no tendría nada que ver con la protección de las obras de arte. ${ }^{16}$ Sin embargo, consideramos que fue precisamente la preservación del patrimonio lo que motivó el dictado de esta ley. Como bien ha señalado Javier Arce, la aparente contradicción planteada entre la prohibición de los sacrificios y la orden de dejar intactos los templos se salva fácilmente cuando ponemos en relación esta constitución con la legislación sobre los edificios públicos emanada durante el siglo IV: en ella se insiste de forma reiterativa en la necesidad de conservar los monumentos heredados de la Antigüedad, aunque se trate de templos cerrados al culto. ${ }^{17}$ Este mismo autor considera que «no es imposible pensar que el uicarius Macrobio, a la vista de que en algunos templos de Hispania se estaban destruyendo las estatuas [...] reclamase del Emperador intervenir en este sentido». ${ }^{18}$ Esta hipótesis resultaría posible si la presente disposición hubiera estado motivada realmente por una occasio legis. Sin embargo, por nuestra parte, preferimos decantarnos por otra opción diferente: la ley del 399 formaría parte de un programa legislativo más amplio destinado a proteger el patrimonio, por lo que sería muy similar a constituciones enviadas a los gobernantes de otros territorios. Creemos que un indicio de que esta medida no atañe en exclusiva al caso hispano es que también estaba dirigida al vicario de las Cinco Provincias. ${ }^{19}$

16 Geffcken 1929, 180; McKenna 1938, 43.

17 Arce 1986, 137-138. Véase también Arce 2005, 248. Acerca de esta legislación, véase Janvier 1969. Stephen Mckenna (véase nota anterior) presenta una ley como evidencia de que la prohibición de demoler los templos en Hispania no tenía nada que ver con motivaciones artísticas; se trata de Cod. Theod., XVI, 10, 16 [p. 902], igualmente del año 399, en la que se ordenaba la destrucción de los santuarios campestres. Esta medida fue promulgada por Arcadio y dirigida al prefecto del pretorio oriental Eutiquiano. Debemos recordar en este punto, no obstante, que los gobernantes de la mitad occidental del Imperio romano siempre mostraron más interés en proteger el patrimonio que los de Oriente, un territorio este último donde el cristianismo se hallaba aún más profundamente arraigado y en el que se producían más ataques contra el patrimonio pagano.

18 Arce 2006, 119.

19 Aparte de esta constitución, no disponemos de otras leyes dirigidas a Hispania que traten del tema que nos ocupa, con lo que de nuevo nos enfrentamos a la consabida escasez documental; esto a priori podría generar la falsa impresión de que en este territorio no existían excesivos problemas en relación con los templos. Con todo, aquí debemos precisar algunas consideraciones. Esta ley proviene, como ya hemos dicho, del Codex Theodosianus, una compilación legislativa publicada en el 438 . Los compiladores no reunieron en ella todas las leyes promulgadas durante el siglo IV y parte del V, y además las medidas tomadas en consideración fueron despojadas de todos aquellos elementos textuales estimados superfluos. Esto resulta fundamental para comprender las leyes en su contexto, pues de entrada implica que debieron existir otras muchas que no se nos han conservado sencillamente porque no fueron recogidas en el Teodosiano. En el caso que nos ocupa, lo que acabamos de exponer afectaría de dos maneras. En primer lugar, como ya hemos apuntado, la citada ley del 399 con seguridad no estaría tratando de un problema específico del territorio hispano, sino que pudo ser bien una copia de una disposición con carácter más general enviada también a los gobernadores de otros territorios. En segundo lugar, pudieron existir otras leyes de temática similar enviadas a Hispania, pero que no fueron recogidas en el Codex Theodosianus ni en otras colecciones, por lo que, en consecuencia, no han llegado hasta nosotros. 
El principal testimonio para conocer el estado del paganismo en Hispania durante el siglo IV proviene de los autores cristianos. El problema radica en que estas referencias son muy vagas, generales y estereotipadas. Los eclesiásticos hispanos no criticaron ningún culto concreto, sencillamente porque no estaban interesados en ello. Las referencias a la idolatría acostumbran a hallarse en homilías destinadas a un público cristiano al que en teoría ya no había necesidad de convertir. Y además muchas veces da la impresión -en contraste con lo que leemos en predicadores de otros territorios - de que el comportamiento de estos feligreses era impecable, y que ellos no mostraban ningún tipo de inclinación por practicar fiestas y rituales de raíz paganizante, lo cual resulta muy difícil de creer. Incluso podemos llegar a obtener la falsa sensación de que en esos momentos las religiones politeístas estaban en retroceso y casi extinguidas, y, por tanto, no suponían ningún tipo de amenaza para los líderes cristianos y para su grey. Gregorio, obispo de Elvira aproximadamente entre el 357 y el 392, constituye un buen ejemplo de este proceder. Así, en una de sus homilías se refería a los gentiles y afirmaba que el paganismo se hacía cruel en la persecución, justo en una época en la que las persecuciones habían finalizado desde hacía ya varias décadas. ${ }^{20}$ En otro sermón explicaba alegóricamente las palabras de Dios respecto a cómo había de ser la víctima ofrecida (Lv 22,22): sin sarna ni herpe: la sarna aludiría a los pecados de los gentiles -la idolatría, el incesto, el adulterio, el homicidio y la homosexualidad, entre otros-, mientras que el herpe representaría al conjunto de los herejes. ${ }^{21}$ Observamos la misma poca precisión en las obras espurias que habían sido atribuidas a Gregorio de Elvira; al igual que en las genuinas de este, las menciones al politeísmo aparecen formando parte de interpretaciones alegóricas de pasajes de las Escrituras. ${ }^{22}$

No obstante, las tradiciones paganas continuaban bien vivas y persistían incluso entre la población cristiana, como podemos comprobar a través de las palabras de Paciano, obispo de Barcelona durante la segunda mitad del siglo IV. Este escribió en los primeros años de su episcopado, segu-

20 Gregorius Ilib., In Cant. Cant., IV, 25 [p. 205].

21 Gregorius Ilib., Tract. Orig. de libr. SS. Script., 10, 23 [p. 81].

22 Ps.-Gregorius Ilib., De Salom., 29 y 35-37 [p. 258-259]; Id., De diu. gen. lepr., 10 y 20 [p. 280 y 282]. Gregorio también tiene un papel importante en el Libellus precum (384). El episodio, absolutamente fabuloso, presenta a Gregorio enfrentándose a Osio, cuando al regresar este a Hispania tras haber firmado en el Concilio de Sirmio (357) -y por tanto, haber aceptado los postulados arrianos-, intentó que el resto de obispos hispanos comulgaran con los heréticos. Gregorio se resistió, por lo que fue convocado por el vicario Clementino, un pagano - personaje conocido solo por esta fuente-. Osio reclamó el exilio del iliberritano, a lo que se negó Clementino hasta que Osio hubiera depuesto antes a Gregorio. Cuando Osio estaba a punto de pronunciar su sentencia de destitución de la sede episcopal, Gregorio rezó a Dios pidiéndole protección. Acto seguido, Osio se desplomó muerto en el suelo, milagro que provocó la conversión de Clementino (Marcellinus et Faustinus, De confess. uer. fidei, 9, 33-10, 40 [p. 368-370]). El mismo texto menciona que, en otro momento, algunos individuos del pueblo excitados por los rivales de Gregorio irrumpieron en una iglesia de un partidario de este obispo, cogieron el altar y lo depositaron a los pies de un ídolo en un templo (Marcellinus et Faustinus, De confess. uer. fidei, 20, 76 [p. 378]). Aunque el episodio no goza de verosimilitud histórica, tiene el valor de mostrar la importante presencia pagana en Hispania durante la segunda mitad del siglo IV. Véase: McKenna 1938, 45-46; Fernández Ubiña 1997, 110-113. ramente a mediados de la cuarta centuria, una obra titulada Ceruulus $^{23}$ en la cual reprochaba a sus feligreses algunos de los excesos cometidos por ellos durante las celebraciones de las calendas de enero, especialmente la costumbre del ceruulum facere; es decir, disfrazarse adoptando la apariencia de un ciervo. Por desgracia, esta obra no ha llegado hasta nuestros días, pero podemos conocerla gracias a la descripción que este obispo realizó en su De paenitentibus. Al inicio de este escrito, Paciano recuerda cómo fracasó en el pasado, cuando redactó el Ceruulus para corregir a sus feligreses y no solo no consiguió su objetivo sino que incluso la gente practicó esta tradición todavía con más empeño. El prelado se culpa de esto, ya que considera que había muchos individuos que no sabían qué era "hacer el ciervo" hasta que él se lo mostró con sus reprobaciones. ${ }^{24}$ Paciano no llega a decir de forma explícita que esta fiesta tuviese lugar durante las calendas de enero, pero contamos con el testimonio de otros autores de fuera de Hispania que nos confirman que esta celebración de carácter carnavalesco se celebraba en dicha ocasión. ${ }^{25}$ Nos hallamos ante una costumbre superviviente de los cultos indígenas y que pone de manifiesto cómo esta época contempló un resurgir de las tradiciones autóctonas. De hecho, el ceruulum facere tan solo se documenta en Hispania, Italia y Galia, territorios con una fuerte presencia celta. En consecuencia, resulta muy posible que esta mascarada fuera una reminiscencia del culto antaño dado al dios cornudo Cernunnos. Tal vez el culto en sí ya había sido destruido por el cristianismo, pero las prácticas ligadas a él bien pudieron haber recobrado fuerza tras el retroceso de las instituciones romanas en Occidente. ${ }^{26}$

Otro texto imprescindible para conocer el estado del paganismo en Hispania durante la segunda mitad del siglo IV corresponde a la decretal que el papa Siricio envió al obispo Himerio de Tarragona el 11 de febrero del 385. ${ }^{27}$ Esta carta era la respuesta a otra precedente que Himerio había remitido al papa Dámaso planteándole diversas cuestiones, pero habiendo fallecido Dámaso probablemente el 11 de diciembre del 384, ${ }^{28}$ fue su sucesor, Siricio quien respondió al prelado de Tarragona. La misiva de Himerio no se conserva, pero resulta posible rehacerla en parte a partir de la epístola papal. Entre las diferentes dudas expuestas, se hallaba la concerniente a qué hacer con los apóstatas. Observamos

${ }^{23}$ En la noticia biográfica consagrada a Paciano en el De uiris illustribus, Jerónimo se hace eco de esta obra y la denomina Ceruus (Hieronymus, De uir. illustr., 106 [p. 49]). Este título aparece a veces en caracteres griegos en algunas ediciones de la obra jeronimiana. Sin embargo, el propio Paciano dejó bien claro en otro de sus escritos que el título de su opúsculo era Ceruulus, ya que lo redactó para censurar la costumbre existente entre sus fieles de disfrazarse de ciervo durante las fiestas de Año Nuevo (Pacianus, De paen., 1, 3 [p. 10]).

24 Pacianus, De paen., 1, 2-3 [p. 9-10]. Véase: McKenna 1938, 46-47; Meslin 1970, 81-82; Martínez 1972, 496-497; Hillgarth 1980, 12; Díaz y Torres 2000, 240; Martínez Maza, Sanz y Díaz 2007, 144; Blázquez 2010, 164-171.

25 Una relación de estas fuentes puede leerse en Jiménez 2017b, 166-170. Véase también: Denk 1906; Rohlfs 1948-1949; Arbesmann 1979.

26 Peter Brown (2012, 29 y 34) señala que el elemento indígena nunca llegó a desvanecerse por completo bajo el dominio romano, por lo que recobró de nuevo protagonismo tras el repliegue del Imperio de muchas de las zonas que había ocupado anteriormente.

27 Siricius, Ep., 1 [c. 1131-1147]. Acerca de esta decretal, véase Vilella 2004.

28 Vilella 2004, 338, n. 10. 
aquí que en Hispania, al menos en la Tarraconense, resultaba un problema preocupante la existencia de antiguos cristianos que se habían profanado con el culto de los ídolos y con la contaminación de los sacrificios. ${ }^{29}$ La contestación de Siricio fue concisa: los apóstatas debían ser apartados del cuerpo y de la sangre de Cristo, precisamente el medio por el que se habían redimido hacía tiempo; pero si alguno de ellos se arrepentía, se le permitiría hacer penitencia durante el resto de su vida a fin de poder obtener la gracia de la reconciliación en su último día. ${ }^{30} \mathrm{Al}$ final de la epístola, el papa instó a Himerio a cumplir sus disposiciones y a transmitirlas además a todos los obispos tanto de su diócesis como de las provincias vecinas, haciendo acompañar la decretal papal de una carta escrita por el propio obispo tarraconense. ${ }^{31} \mathrm{La}$ pregunta que aquí se nos plantea es la siguiente: ¿se trata realmente en este caso de verdaderos apóstatas -es decir, de antiguos cristianos que formalmente han renunciado a la fe de Cristo para regresar al culto idolátrico- o de cristianos que tan solo han participado en determinadas actividades - como asistir a un sacrificio o tomar parte en un banquete ritual- junto con individuos considerados paganos? Realmente, nos hallamos ante una cuestión difícil de responder.

Un escrito atribuido a Prisciliano, ${ }^{32}$ redactado probablemente en el 378/380, ${ }^{33}$ también recoge interesantes alusiones a la idolatría. El autor mostraba en él abiertamente su desprecio por los dioses paganos y confesaba que antes de su conversión conocía todas esas cosas contrarias a la fe y leía las historias de estas divinidades para instruir su mente. Asimismo, solicitaba que fuera anatema quien llamara dioses a los entonces considerados planetas -el Sol, la Luna, Júpiter, Marte, Mercurio, Venus y Saturno-, astros asociados al ritual de los sacrificios y al error de los paganos, y que fuera asimismo anatema quien venerara a los ídolos detestables dignos de la gehena. A continuación, se dedicaba a

29 Siricius, Ep., 1, 4 [c. 1136]. Véase Vilella 2004, 341.

30 Siricius, Ep., 1, 4 [c. 1136]. Véase: McKenna 1938, 46; Arce 1986, 143; Vilella 2004, 346-347; Martínez Maza, Sanz y Díaz 2007, 143.

31 Siricius, Ep., 1, 20 [c. 1146]. Véase Vilella 2004, 366-367.

32 Este opúsculo es el primero de los once Tractatus del códice de Würzburg (datado en los siglos V-VI). Al igual que el resto, es anónimo, por lo que la cuestión de su autoría ha generado un debate todavía no resuelto. Su descubridor y editor, Georg Schepss, consideró que todos se debían a una misma mano, e identificó a este autor con Prisciliano (Schepss 1889, VII-VIII). Mientras que diversos autores han seguido esta posición unitaria, otros se han decantado por una postura analista $y$, aunque reconocen que todos los tratados poseen un contenido priscilianista, rechazan la autoría única así como que estos escritos pertenezcan a una misma época y tengan una misma razón de ser. No obstante, incluso los analistas aceptan en su mayor parte que el autor de los tres primeros tratados es Prisciliano o, al menos, alguien muy cercano a él - postura que aceptamos-. El Tractatus 1 es el único del códice que no lleva título, por lo que su editor lo denominó Liber apologeticus a partir de su contenido. Al respecto, véase: Vilella 1997, 506, n. 11-12; Crespo 2009, 31-38.

${ }_{33}$ No existe en el Liber apologeticus ningún elemento que permita datarlo de una manera precisa. El autor se dirige a un conjunto de obispos, probablemente reunidos en una asamblea episcopal, lo que ha llevado a la mayor parte de los investigadores a identificar dicho sínodo con uno de los dos concilios convocados durante la controversia priscilianista: Zaragoza (378/380) y Burdeos (383/384). Véase Vilella 1997, 506-507. Puede leerse un estado de la cuestión en Chadwick $1978,72-77$, quien concluye que «el primer tratado es obra del mismo Prisciliano y una exposición formal presentada al concilio de Zaragoza» (Chadwick 1978, 77), después de exponer una larga serie de razones que consideramos válidas y que aceptamos. denigrar a estos dioses planetarios y a sus adoradores, mostrando que dichos númenes simbolizaban pecados y vicios que al ser conocidos harían que la gente rechazara las tinieblas y deseara la luz del Señor. ${ }^{34}$ La insistencia de Prisciliano en condenar a estas deidades proviene seguramente de su deseo de exculparse de la acusación de haber estudiado astrología durante su juventud, algo que el autor admitía, aunque insistiendo en que dichas lecturas le ayudaron a ver que la religión pagana se basaba en ridículas supersticiones. Por otro lado, algo más adelante Prisciliano volvía a pedir que fuera declarado anatema, e incluso perseguido con la espada - castigo reservado a los acusados de magia - , todo aquel que consagrara mediante mágicos ensalmos la degustación de sus primeros frutos y que ofrendara un ungüento al Sol y a la Luna con la esperanza de que estos alejaran cualquier posible maldición arrojada sobre sus cosechas. ${ }^{35}$ Nos hallamos aquí ante la refutación de la acusación lanzada por Itacio: practicar rituales mágicos de tipo rural relacionados con la meteorología, una imputación - la de la práctica de la magia - que posteriormente tendría un peso fundamental en el proceso de Tréveris. Como bien ha señalado Stephen McKenna, el autor no habría tenido necesidad de insistir en tales puntos si dichas creencias y prácticas no continuaran bien presentes en Hispania. ${ }^{36}$

En el paso entre los siglos IV y V, el presbítero Eutropio dirigió su obra De similitudine carnis peccati ${ }^{37}$ a una ferviente cristiana, perteneciente seguramente a una familia acaudalada. Al final de este opúsculo, el sacerdote realizaba una alabanza de esta mujer y recordaba que adoctrinaba a los paganos y a los bárbaros de la zona hablándoles en la lengua vernácula acerca de Dios; y asimismo también mencionaba que estos individuos eran bárbaros tanto por su lengua como por su manera de pensar, dado que consideraban que sus dioses eran inmortales. ${ }^{38} \mathrm{El}$ autor no mencionó explícitamente a quiénes estaba haciendo referencia, pero dado que este desarrolló su actividad en la zona pirenaica, muchos investigadores han considerado que las posesiones de la dama noble a la que se dirige Eutropio se hallarían tal vez en el norte de Hispania y que probablemente los adoctrinados serían los vascones. ${ }^{39}$

Por otro lado, dentro de la serie de los cánones pseudoiliberritanos, secularmente identificada de manera errónea con las actas de un concilio celebrado en Elvira a inicios del siglo IV, ${ }^{40}$ contamos con numerosas disposiciones que alu-

34 Priscillianus, Lib. apol., [p. 17]. Véase: McKenna 1938, 47-48; Vilella 1997, 507; Crespo 2009, 329-370.

35 Priscillianus, Lib. apol., [p. 24]. Véase: Chadwick 1978, 77-82; Martínez Maza, Sanz y Díaz 2007, 144; Crespo 2009, 480-484.

36 McKenna 1938, 48.

37 Esta obra había sido atribuida erróneamente a Paciano por Morin (1913, 81-150), pero José Madoz (1942, 27-54) la restituyó a Eutropio. Posteriormente, Antonio García y Bellido $(1967,27-28)$ lo identificó con el obispo Eutropio de Valencia (S. VI), por lo que situó el escenario de la evangelización de los bárbaros en el levante peninsular. No obstante, Sebastián Mariner $(1976,273-274)$ retomó la hipótesis de Madoz, de tal manera que, como veremos, identificó a los bárbaros que recibían adoctrinamiento con los vascones.

38 Eutropius, De simil. carn. pecc., [p. 555]. Véase: Arce 1986, 143; Martínez Maza, Sanz y Díaz 2007, 144.

39 Mariner 1976, 274; Sayas 1985, 47; Segura 2001, 162 y 178.

40 La historiografía ha sostenido tradicionalmente que el sínodo más antiguo celebrado en Hispania tuvo lugar en la ciudad granadina de Elvira en algún momento indeterminado de inicios del siglo IV. A 
den a la idolatría. Dos de ellas nos llaman particularmente la atención: se trata de los cánones 1 y 59 , que prohibían a los cristianos asistir y participar en los sacrificios del culto romano tradicional. Concretamente, el canon 1 apartaba de la comunión - ni siquiera en peligro de muerte- a todos aquellos fieles adultos que acudieran a un templo a sacrificar. ${ }^{41}$ Por su parte, el 59 prohibía a los cristianos subir al templo para realizar un sacrificio o incluso para contemplarlo; esta última disposición establecía una penitencia de diez años. ${ }^{42}$ Como bien ha puesto de manifiesto Josep Vilella, ${ }^{43}$ la diferencia en la penitencia para un mismo delito indica que ambas disposiciones presentan cronologías y/o procedencias diferentes. Este autor compara el contenido de estos preceptos con otros testimonios coetáneos, especialmente de tipo disciplinar y legislativo, y llega a la conclusión de que la intransigencia en materia disciplinar mostrada en estos cánones los sitúa en un momento en que los cultos tradicionales habían dejado de contar con el soporte estatal y comenzaban a ser objeto de represión en el plano jurídico, lo que repercutía en un endurecimiento de las condenas eclesiásticas para la práctica de la idolatría. Así pues, en palabras de este investigador, ambos cánones «evidencian, por una parte, que fueron redactados cuando en los templos - o altares- urbanos todavía se celebraban sacrificios públicos y, por otra, que pertenecen a un momento en el que los ritos paganos ya eran objeto de notorias trabas y restricciones por las autoridades civiles $\gg .{ }^{44}$ Esto llevaría a ubicarlos durante la segunda mitad del siglo IV, no más tarde.

este supuesto concilio habrían asistido diecinueve obispos y veinticuatro presbíteros de diversas ciudades de la península ibérica. El resultado del encuentro se habría plasmado en unas actas formadas por nada menos que 81 cánones, un número inusualmente elevado, sobre todo si lo comparamos con las disposiciones emanadas de otros concilios del siglo IV. Pero, sin embargo, la realidad es muy diferente. Los trabajos llevados a cabo por Josep Vilella y por Pere E. Barreda - conjuntamente o por separado- han puesto de manifiesto que este conjunto textual posee una naturaleza muy diferente a la sostenida hasta ahora por la tradición (entre dichos trabajos destacaremos: Vilella y Barreda 2006; Vilella 2014). El prolijo análisis al que especialmente el primero de los investigadores mencionados ha sometido a estos preceptos -a los que cabría denominar más bien "cánones pseudoiliberritanos»ha demostrado que son el resultado de compilar medidas, no siempre sinodales, de procedencias y cronologías diversas; por tanto, esta «colección» posee un carácter no sincrónico. Esto explica las contradicciones existentes en ocasiones entre diversos cánones - caso de 1 y 59discordancia explicable tan solo a partir de la diferente procedencia de ambos textos; una antítesis semejante no podría darse en el interior de unas actas conciliares. Además, tampoco existe conexión entre el conjunto normativo y el prefacio con la lista episcopal recogida en la Hispana. La crítica textual también ha evidenciado que estos textos fueron modificados mediante la adición de glosas o interpolaciones e incluso añadidos y supresiones, lo cual conllevó a la aparición de nuevos cánones, a veces con nuevas casuísticas, que se acabarían incorporando posteriormente a la compilación. En resumen, y en palabras de Josep Vilella $(2005,98)$, los cánones pseudoiliberritanos «presentan una historia textual enrevesada, caracterizada tanto por adiciones y eliminaciones en el elenco como por modificaciones de algunos textos. Se trata de un proceso - en el que intervinieron varias manosefectuado durante un intervalo temporal que no podemos concretar, aunque ya parece haber concluido a finales del siglo VI, pues entonces la composición pseudoiliberritana había salido del «taller» - probablemente bético- donde fue confeccionada o ensamblada».

${ }_{41}$ Can. ps.-llib., 1 [p. 570].

42 Ibídem, 59 [p. 577].

43 Vilella 2005, 101.

44 Ibídem, 131.
Otras disposiciones de los cánones pseudoiliberritanos atinentes a la idolatría aluden a los flamines que, aunque convertidos al cristianismo, continuaban ejerciendo este sacerdocio pagano. Así, aquellos que habían recibido el bautismo, en el caso de que hubieran sacrificado, cometido un homicidio o consumado adulterio, no recibirían la comunión ni en el momento de su muerte (c. 2). Si tan solo habían presentado alguna ofrenda, pero absteniéndose de los sacrificios, recibirían la comunión al final de sus días tras haber realizado la debida penitencia (c. 3). En el caso de que el flamen fuera catecúmeno, podría ser admitido al bautismo al cabo de tres años siempre que se abstuviera de los sacrificios (c. 4). Aquellos otros sacerdotes de los gentiles que tan solo llevaban coronas, pero que no sacrificaban ni contribuían con su dinero al mantenimiento del culto, podrían recibir la comunión al cabo de dos años (c. 55). Los possessores tenían prohibido recibir como parte de sus rentas aquello que había sido ofrecido a los ídolos, bajo pena de exclusión de la comunión por cinco años (c. 40). También resultan interesantes las medidas que regulaban las relaciones personales de los cristianos con los paganos. De este modo, los cristianos tenían vedado entregar a sus hijas en matrimonio a los gentiles, para evitar que su juventud las pudiera conducir al "adulterio del alma», es decir, a la idolatría (c. 15). Si el individuo en cuestión fuera un sacerdote pagano, el padre de la joven no recibiría la comunión ni al final de su vida (c. 17). Además, si un fiel cometía adulterio con una gentil, debería cumplir una penitencia de cinco años antes de ser admitido de nuevo a la comunión (c. 78). Por otro lado, otra disposición decretaba que si una prostituta se había casado y posteriormente deseaba convertirse a la fe cristiana no se le opondría ningún tipo de impedimento (c. 44). Tampoco se negaba la conversión a un gentil que, hallándose en peligro de muerte, solicitara su entrada en el cristianismo (c. 39). Otro canon exigía a los fieles que no permitieran la existencia de ídolos en sus casas, ni siquiera aquellos que pudieran poseer sus siervos, salvo en el caso de que temieran su violencia (c. 41). Evidentemente, el peligro de la apostasía siempre se hallaba muy presente, por lo que una nueva disposición estipulaba una penitencia de diez años para aquellos apóstatas que desearan reintegrarse a la religión cristiana (c. 46). El fanatismo de algunos individuos en su afán por destruir ídolos podía conducirles en ocasiones a la muerte; sobre estos, otro canon decretó que no fueran contados entre los mártires (c. 60). Otras medidas señalaban: la exclusión de la comunión de por vida para todo aquel que hubiera cometido homicidio por medio de la magia (c. 6); la expulsión de la iglesia de ex aurigas y pantomimos que tras bautizarse hubieran retomado sus antiguos oficios (c. 62); y el apartamiento de la iglesia de todo duunviro cristiano durante el año que durase su magistratura, seguramente porque en el ejercicio de su cargo debía patrocinar espectáculos paganos (c. 56). ${ }^{45}$

45 Esta última disposición nos trae inevitablemente a la memoria la epístola de Inocencio I a los obispos reunidos en Toledo, de inicios del siglo V; en ella, el prelado romano lamentaba que individuos que habían organizado ludi durante el ejercicio de su magistratura municipal hubieran alcanzado más tarde el sacerdocio, por lo que prohibió que fuera ordenado como tal ningún curial que hubiera ofrecido espectáculos o hubiese desempeñado un sacerdocio pagano (Innocentius, Ep., 3, 4, 7; 6, 9 [c. 491-492]). 
El siguiente testimonio relevante, tras la laguna documental del siglo $\mathrm{V}$, lo leemos en la siguiente centuria. Se trata, evidentemente, de Martín de Braga, cuyo De correctione rusticorum es todo un referente en este tema de estudio. Su obra está dirigida a los fieles, es decir, a cristianos ya bautizados, puesto que en un momento dado Martín alude al juramento formulado durante la ceremonia del bautismo. ${ }^{46}$ También menciona toda una serie de costumbres enraizadas en el más añejo paganismo que eran practicadas por sus feligreses. De este modo, el obispo les reprochó, entre otras cosas, que, designaran los días de la semana con los nombres de los dioses paganos; ${ }^{47}$ que celebraran un día de las polillas y de los ratones, a los que veneraban con el fin de que respetaran las cosechas; ${ }^{48}$ igualmente que, mediante el encendido de velas, rindieran culto a las piedras, a los árboles y a las fuentes, así como a las encrucijadas; que tomaran augurios y creyeran en la adivinación; que celebraran las calendas, en especial las de enero, ${ }^{49}$ y otras fiestas, como las Vulcanales; que durante estas festividades adornaran las mesas y colocaran ramas de laurel, seguramente sobre sus puertas; que prestaran atención al pie con el que comenzaban a caminar; que derramaran grano y vino en el fuego de un tronco y que arrojaran pan a las fuentes; que invocaran a Minerva mientras tejían; que eligieran el viernes (el día de Venus) para casarse y que atendieran a un día propicio para iniciar un viaje; y que hechizaran hierbas invocando el nombre de los demonios para encantarlas..$^{50}$ Como afirmó Martín: obseruationes istae omnes paganorum sunt. ${ }^{51}$

Las alusiones a la idolatría por parte de autores del siglo VII resultan ciertamente circunstanciales. Podemos recordar, por ejemplo, a Isidoro de Sevilla, quien en su lucha contra las fiestas celebradas el día 1 de enero, trató de adaptar esta festividad a la idiosincrasia cristiana, convirtiéndola en una jornada de ayuno y oración. Así, dedicó un capítulo de

\footnotetext{
46 Martinus Brac., De corr. rust., 15 [p. 196-197].

47 Ibídem, 8-9 [p. 188-189].

48 Ibídem, 11 [p. 190].

49 Ibídem, 10 y 16 [p. 189 y 198].

50 Ibídem, 16 [p. 198]. Véase Jiménez 2017a.

51 Martinus Brac., De corr. rust., 11 [p. 190]. Según Sanz 2003
} 12-13, la gran cantidad de tópicos literarios que leemos en algunos de los sermones relativos al paganismo de Cesáreo de Arlés o de Martín de Braga los hace sospechosos «de responder a un modelo previamente elaborado [...] que les prefigura no tanto como documentos históricos cuanto como manuales de persecución del paganismo». Disentimos de esta afirmación; es cierto que la repetición de algunos de estos tópicos responde a préstamos literarios - algo del todo habitual en la literatura antigua-, pero esto no va en menoscabo de su calidad como documento histórico; en efecto, por lo que respecta a Cesáreo, sus biógrafos nos explican que este predicaba tanto en la basílica urbana como en las iglesias rurales (Vit. Caes., II, 20 [p. 272]); y en cuanto a Martín, debemos recordar que el segundo Concilio de Braga exhortaba a los obispos - en su visita anual a la diócesis - a adoctrinar a los fieles para que evitasen el pecado de idolatría y otros crímenes contrarios a la religión (Conc. Brac. II, 1 [p. 118-119]). Todo esto acercaba a los obispos, bien directamente bien a través de los sacerdotes de parroquias rurales, a las costumbres de la gente del campo, con lo que las denuncias de sus sermones no responderían por tanto a meros tópicos, sino a una realidad de la que ellos tenían conocimiento. Respecto a la repetición de unos mismos tópicos en sermones, cánones conciliares y penitenciales, hacemos nuestras las palabras de Schmitt 1992, 41: «la repetición de los mismos cánones durante siglos pone a todas luces de manifiesto la continua presión, al menos hasta el siglo XII, de prácticas y creencias reales, con independencia de la fidelidad de los testimonios eclesiásticos». su De ecclesiasticis officiis - con textos tomados en buena parte del sermón 192 de Cesáreo de Arlés- a explicar la razón por la cual la Iglesia había ubicado un ayuno en dicha jornada: a causa del error de los paganos, quienes adoraban como a un dios a Jano, el cual en realidad había sido tan solo un príncipe de los gentiles. ${ }^{52}$ Por su parte, Valerio del Bierzo relataba cómo unos fieles destruyeron los ídolos que algunos individuos todavía adoraban en un monte retirado..$^{53} \mathrm{En}$ ese mismo siglo, la Vita Amandi recordaba cómo los vascones se entregaban aún en esa época a la toma de augurios y a la práctica de la idolatría. ${ }^{54}$

Las principales referencias a pervivencias idolátricas durante estas centurias se encuentran recogidas en algunos cánones de los concilios toledanos. ${ }^{55}$ En el tercer Concilio de Toledo (589), celebrado bajo Recaredo, leemos la primera prescripción dirigida a obispos y jueces para que investigaran cualquier atisbo de paganismo, destruyeran todos los ídolos descubiertos y castigaran a los idólatras con todo género de condenas, a excepción de la de muerte. Los obispos y jueces que desatendieran esta obligación serían excomulgados, al igual que aquellos señores que permitieran tales actividades a los siervos de sus fundos. ${ }^{56}$ En el mismo sínodo se tomó una medida muy interesante: se prohibió la costumbre existente entre el pueblo de festejar los natalicios de los santos con danzas y cánticos, pues los obispos la juzgaban una actitud irreligiosa e indecente. ${ }^{57}$ Seguramente, nos hallamos aquí ante la pervivencia de unas manifestaciones festivas que arraigaban en antiguas celebraciones de divinidades paganas y que más tarde pasaron a engrosar el acervo cultural cristiano; en efecto, al abrazar la fe de Cristo, muchos de los neoconversos no abandonaron sus antiguas costumbres, sino que sencillamente las adaptaron a su nueva religión. Por esta razón, los obispos estaban equivocados al creer que los que danzaban durante las celebraciones martiriales lo hacían solo por amor al libertinaje e imbuidos de un espíritu pagano. ${ }^{58}$ Mucho más probablemente, nos

52 Isidorus, De eccl. off., I, 41 [p. 46-47]. Véase: McKenna 1938, 119; Díaz y Torres 2000, 246-247; Jiménez 2005, 72; 2017b, 177-180.

53 Valerius Berg., Repl. serm. a prim. conu., 2 [p. 280]. Véase: Aherne 1949, 187; Hillgarth 1980, 39.

54 Vit. Amand., 20 [p. 443-444]. Véase Segura 2001, 148.

55 Sanz 2003, 29-30, señala que el paganismo no podía ser un fenómeno marginal en la Hispania visigoda, ya que de haber sido así no hubiera merecido ser tratado en los concilios toledanos, los cuales gozaban de carácter general. Véase también Crespo 2004, 187-188.

56 Conc. Tol. III, 16 [p. 122-123]. Véase: McKenna 1938, 117; Hillgarth 1980, 15; Blázquez 1985, 156-157; Sanz 2003, 23 y 118; Jiménez 2005, 62.

57 Conc. Tol. III, 23 [p. 131-132]. Véase: McKenna 1938, 116; Hillgarth 1980, 17; Jiménez 2005, 23. Acerca de la relación del cristianismo con la danza, remitimos al artículo de Donatella Tronca en este mismo volumen. Véase también: Resta 2014; 2015; Tronca 2017a; 2017b; 2019.

58 A inicios del siglo VI, Cesáreo de Arlés censuró a aquellos individuos, en teoría cristianos, que durante las fiestas de los mártires se emborrachaban, cantaban canciones deshonestas y bailaban de manera diabólica, y, lo que era lo peor para el obispo, todo esto lo realizaban delante de la basílica martirial. Cesáreo les reprochaba que cuando realizaban tales actividades - según él, por amor al desenfreno, no a Dios - se perdían ellos mismos y perdían a los demás, y que, aunque tal vez habían acudido como cristianos ante la iglesia, se retiraban de ella como paganos, pues como tales se habían comportado; Caesarius Arel., Serm., 13, 4; 55, 2 [p. 67 y 242]. Ya en territorio hispano, a finales del siglo VI Liciniano de Cartagena estimaba que era mejor que la gente pasara el domingo en su casa entregada a diversos quehaceres que 
hallamos ante una forma alternativa de devoción cristiana, fruto de adecuar a esta religión una serie de conductas y rituales de creencias anteriores que existían en estos territorios antes de la implantación del cristianismo.

El duodécimo Concilio de Toledo (681), celebrado bajo Ervigio, volvió a legislar extensamente sobre la idolatría, recordando que su finalidad no era castigar, sino corregir a los pecadores, por lo que ya de entrada se descartaba la pena de muerte. Los obispos y prohombres reunidos en este sínodo avisaban a los adoradores de ídolos, piedras, fuentes y árboles, y a los que encendían hogueras con este objetivo cultual de que ellos mismos se condenaban a muerte - se entiende espiritual (muertos a los ojos de Dios) - al entregarse a su pecado. Los responsables de la investigación seguían siendo los obispos y los jueces, quienes debían encargarse de destruir los objetos de culto. Por lo que respecta a los idólatras, si estos eran siervos, debían ser azotados y entregados encadenados a sus señores, quienes tenían que jurar que en adelante los vigilarían para que no cayeran de nuevo en el mismo pecado. Si no lo hacían así y se desentendían del condenado, este quedaba bajo la potestad del rey y el dominus negligente era excomulgado y además perdía sus derechos sobre su siervo. Si, por el contrario, el culpable era un individuo libre, recibía el castigo de la excomunión perpetua y del exilio. ${ }^{59}$ Estas medidas fueron confirmadas dos años después, en el decimotercer Concilio de Toledo, celebrado también bajo Ervigio. ${ }^{60}$

El decimosexto Concilio de Toledo (693), celebrado bajo Egica, volvió a abordar el tema de una manera todavía más minuciosa. Los reunidos en este sínodo reconocían que el problema de la idolatría persistía en los territorios del reino. Las categorías de pecadores mencionados volvían a ser los adoradores de ídolos, piedras, fuentes y árboles, así como aquellos que encendían hogueras, a los que se añadían en esta ocasión los augures y los encantadores; la enumeración se cerraba con un significativo multaque alia quae perlongum est enarrare. ${ }^{61}$ También se insistía en que la finalidad de la medida era la correctiva, no la punitiva; es decir, rescatar al pecador de la influencia del diablo y restituirlo a Dios. ${ }^{62}$ Dado que los obispos y las autoridades seculares congregados en esta reunión reconocían que la idolatría era un problema que se había intentado solventar en concilios anteriores, acudieron a los cánones emanados de dichos sí-

no que lo pasara bailando y cantando canciones deshonestas para excitar la lascivia; Licinianus Carth., Ep., 3, 2 [p. 127-128]. Véase: Madoz $1948,74-75$ (quien destaca la dependencia de Liciniano en este pasaje de los escritos de Agustín de Hipona); González Fernández 1995, 297 (quien sostiene que «aquí Liciniano no nos plantea una situación totalmente real sino que una vez más [...] revela una dependencia directa de los escritos de Agustín»); Díaz y Torres 2000, 245; Sanz 2003, 27. En la siguiente centuria, Valerio del Bierzo criticaba al sacerdote corrupto Justo por entregarse a cantos y danzas licenciosas de una manera propia de la lujuria del teatro; Valerius Berg., Ord. querim. pref. discr., 13 y 16 [p. 262 y 264-266]. Véase: McKenna 1938, 130-131; Aherne 1949, 176; Hillgarth 1980, 17; Frighetto 1999; Díaz y Torres 2000, 245.

59 Conc. Tol. XII, 11 [p. 182-184]. Véase: McKenna 1938, 128-130; Martínez 1972, 497-498; Hillgarth 1980, 16; Blázquez 1985, 156; Sanz 2003, 23 y 118; Jiménez 2005, 64.

60 Conc. Tol. XIII, 9 [p. 245-246]. Véase Jiménez 2005, 64.

61 Conc. Tol. XVI, 2 [c. 537]: illi diuersis suadelis decepti cultores idolorum efficiuntur, ueneratores lapidum, accensores facularum, excolentes sacra fontium uel arborum, auguratores quoque seu praecantatores, multaque alia quae perlongum est enarrare.

62 Ídem [c. 537]. nodos a fin de utilizarlos en la elaboración del nuevo dictamen. Tras examinarlos y verificar que se mostraban del todo razonables, decretaron que los responsables de mantener la pureza de la fe continuaran siendo los obispos y los jueces, a los que además incorporaron los presbíteros. En el caso de que descubrieran a un individuo entregado a la idolatría, independientemente de su género o condición, debían detener al culpable para que fuera castigado. En cuanto a los dones presentados a los ídolos, habrían de ser ofrecidos a las iglesias vecinas ${ }^{63}$ delante de aquellos que habían intentado efectuar tal ofrenda. ${ }^{64}$ El presente canon también establecía las penas pertinentes para aquellos hombres de iglesia y jueces que descuidaran su obligación: habrían de realizar penitencia durante un año, tiempo durante el cual dejarían de ejercer su cargo y serían sustituidos por el individuo que el rey designase para esta función. Si alguien impedía la investigación de los obispos y los jueces, sería considerado anatema; si tenía origen noble, sería además condenado a pagar una multa de tres libras de oro al fisco; si no pertenecía a la nobleza, el castigo se endurecía notablemente, pues consistía en cien azotes, decalvación y pérdida de la mitad de los bienes, que irían a parar al fisco. ${ }^{65}$

A modo de conclusión, consideramos que las quejas y condenas de los autores cristianos no eran infundadas. No negamos que en muchos casos hubiera una cierta dosis de exageración, pero no creemos de ninguna manera que estas respondieran únicamente a sus miedos y preocupaciones, como ha sostenido algún autor moderno. ${ }^{66}$ Como hemos podido ver, en sus críticas los obispos aludían sobre todo a determinados elementos naturales, especialmente árboles, piedras y fuentes. ${ }^{67}$ Esto también lo documentamos en la Galia de inicios del siglo VI a través de los sermones de Cesáreo de Arlés, quien llegó a pedir a sus oyentes que, si tenían conocimiento de este tipo de culto, acabasen con él, por ejemplo, talando los árboles. ${ }^{68}$ Lo que aquí vemos

63 El control de las ofrendas no era una cuestión baladí, dado que estas podían constituir una importante fuente de ingresos para una modesta iglesia rural. De ahí el interés de los eclesiásticos en disponer de todos aquellos presentes que antes estaban destinados a los cultos idolátricos. Al respecto, véase Sanz 2003, 30.

64 Conc. Tol. XVI, 2 [c. 537].

65 Ídem [c. 537-538]. Véase: McKenna 1938, 132-133; Martínez 1972, 498; Hillgarth 1980, 16; Blázquez 1985, 157; Sanz 2003, 23 y 30; Jiménez 2005, 65.

66 Como ejemplo, puede verse Hen 1995, 171: "I would suggest that repetitions are, in part, a result of some well-rooted literary conventions, while at the same time they reflect a certain reality which existed at the time of composition. This reality was a mental reality rather than a practical one, and thus it reflects first and foremost the fears and worries which preoccupied the author's mind").

67 Sanz 2003, 54-55 y 126; Crespo 2004, 185 y 193-195.

68 Caesarius Arel., Serm., 14, 4 [p. 72]: quicumque iuxta domum suam aras aut fanum aut arbores profanas ubi, uota reddantur, esse cognouerit, studeat confringere, dissipare atque succidere. En consecuencia, disentimos de la siguiente afirmación de Hen 1995, 165166: «Caesarius does mention trees, fountains and stones as sites of pagan shrines. He also mentions magic, amulets, the celebration of the Kalends of January, the adoration of the moon, and several other non Christian practices. Yet, he never refers to a specific religion which operated in Gaul side by side with Christianity, or to any priest of those supposed pagan religions». En este sentido, estimamos que resulta normal que Cesáreo no especificara ninguna práctica concreta, detallando todos los pormenores del culto popular, ya que lo que a él le interesaba era denunciar la perpetuación de unas prácticas que él consideraba idolátricas, no redactar un tratado de antropología religiosa para legarlo a la posteridad. 
no son los restos del paganismo grecorromano practicados en las ruinas de unos templos rurales, sino las pervivencias de unos cultos prerromanos centrados en torno a diversos elementos de la Naturaleza y llevados a cabo muy probablemente con el fin de propiciar la fertilidad. ${ }^{69}$

No negamos que los actores de estos rituales fueran cristianos en numerosas ocasiones. Pero eran cristianos a menudo de reciente conversión, que habían recibido muchas de estas tradiciones de sus ancestros. En un claro ejemplo de sincretismo religioso, adaptaron muchas de ellas a su nuevo sistema de creencias religiosas, dotándolas de una pátina de cristianismo que en realidad nada tenía que ver con la fe de Cristo, pero que permitió la supervivencia de estas costumbres - como hemos visto con las danzas efectuadas en el aniversario de los mártires-, lo que a su vez motivó el escándalo de los predicadores. ${ }^{70}$ Pero al cristianizar estas costumbres paganas, la gente también estaba favoreciendo paradójicamente la implantación y, a la larga, el triunfo del cristianismo. Dicho en otras palabras, el cristianismo se impuso sobre el paganismo porque él mismo se fue paganizando progresivamente. Al incorporar y absorber diversos elementos del politeísmo, pudo ser aceptado y asimilado más fácilmente por las poblaciones recientemente convertidas. ${ }^{71}$ Pero este fue un proceso lento que necesitó muchos siglos para cimentarse y en el cual se dieron diversas fases: algunas de las prácticas denunciadas como paganas en un inicio por los eclesiásticos fueron toleradas más adelante con una cierta indiferencia al comprobar estos que aquellas ya habían perdido su componente idolátrico, y al final - cuando se vio que se resistían a desaparecer - fueron aceptadas dentro del acervo de las tradiciones cristianas. Como han señalado Pablo Díaz y Juana Torres a propósito de las danzas celebradas en ocasión de los natalicios de los mártires, "se trata de una tradición festiva, incluso lúdica, en la práctica religiosa que a la larga la Iglesia sería incapaz de atajar, optando a la postre por su asimilación por medio de romerías y festividades que [...] no eran sino una nostalgia de lo mágico». ${ }^{72}$ Veamos otro ejemplo ilustrativo de cuanto acabamos de decir: a inicios del siglo $\mathrm{V}$ los habitantes del norte de África encendían hogueras para celebrar el solsticio de verano, justo durante la jornada en la que la

69 Brown 1997, 92, recuerda cómo una vez eliminado oficialmente el culto idolátrico, uno de los principales problemas de los habitantes del Mediterráneo occidental entre finales del siglo $\mathrm{V}$ e inicios del V consistió en cómo concebir la difusa sacralidad del mundo natural que los rodeaba, dado que el $90 \%$ de esa población vivía de la agricultura y de la ganadería, y su economía dependía de los caprichos de la meteorología. "Se creía que, lejos de constituir un espacio neutro, el mundo de la naturaleza estaba plagado de energías sobrenaturales». Por este motivo, tales gentes se imaginaban capaces de influir en este mundus, "de provocar su generosidad y de mantener a raya sus peligros, mediante ritos que se remontaban en casi toda Europa a épocas prehistóricas». Un único Dios resultaba excesivamente lejano como para cubrir tales necesidades, por lo que el cristianismo tuvo que adaptarse para resultar razonable y aceptable a estos individuos.

70 Schmitt 1992, 40: «bajo las apariencias de culto cristiano, las prácticas ancestrales persistían de una forma implícita, o incluso coexistían con él». Por su parte, Peter Brown $(1995,24)$ señala que cuando se abolió el culto politeísta, todo el pasado quedó como un remanente pagano, por lo que cualquier tradición secular se convirtió en sospechosa de ser idólatra («Antiquitas, 'antiquity, mother of all evils', was the last enemy of all true Christians»).

71 Acerca de este tema, véase MacMullen 1997, 103-149.

72 Díaz y Torres 2000, 246
Iglesia había ubicado el natalicio de Juan Bautista, una costumbre que Agustín de Hipona censuró como pagana en el $401 .^{73}$ Sin embargo, algo más de un milenio más tarde, a mediados del siglo XVI, León el Africano describía esta misma costumbre como una reminiscencia cristiana que pervivía en el norte de una África ya musulmana. ${ }^{74}$ La costumbre seguía siendo la misma. Lo que había cambiado era el modo en que era percibida. Pero debemos insistir en que este fue un proceso lento. Durante los siglos aquí tratados (IV-VII), la Iglesia todavía contemplaba tales conductas como de origen indudablemente pagano, aunque fueran realizadas por cristianos. Y en nuestra opinión, esto debería ser lo primordial para nosotros, el modo en que las juzgaban los eclesiásticos, dado que nos resulta imposible conocer la intención de sus practicantes. Para los predicadores, tales individuos no eran christiani, sed pagani, tal y como denunciaba la anónima Homilia de sacrilegiis con la que hemos abierto este estudio.

\section{FUENTES}

Augustinus. 1955. De ciu(itate) Dei. Ed. Bernhard Dombart y Alfons Kalb. CCSL, 47-48. Turnhout: Brepols Publishers.

Augustinus. 1960. Serm(o), 279. PLS, 2, 657-660. Paris: Éd. Garnier Frères.

Augustinus. 1930. Serm(o), 293B. Miscellanea Agostiniana 1, 227-231. Roma: Tipografia Poliglotta Vaticana.

Caesarius Arel(atensis). 1953. Serm(ones). Ed. Germain Morin. CCSL, 103-104. Turnhout: Brepols Publishers.

Can(ones) ps(eudo)-lliberr(itani). 2002. Ed. Josep Vilella y Pere Enric Barreda, «Los cánones de la Hispana atribuidos a un concilio iliberritano: estudio filológico». En I concili della cristianità occidentale. Secoli III-V, 545-579. Studia Ephemeridis Augustinianum, 78. Roma: Institutum patristicum Augustinianum.

Cod(ex) Theod(osianus). 1905. Ed. Theodor Mommsen, Theodosiani libri XVI cum constitutionibus Sirmondianis et leges Nouellae ad Theodosianum pertinentes, 1/2, 1-906: Codex Theodosianus. Berlin: Weidmann.

Conc(ilium) Brac(arense) II. 1950. Ed. Claude W. Barlow, Martini Episcopi Bracarensis opera omnia, 116-123. New Haven: Yale University Press.

Conc(ilium) Tolet(anum) III, 1992. Ed. Félix Rodríguez, La Colección Canónica Hispana, V, 49-159. Madrid: CSIC.

Conc(ilium) Tolet(anum) XII. 2002. Ed. Félix Rodríguez, La Colección Canónica Hispana, VI, 135-204. Madrid: CSIC.

Conc(ilium) Tolet(anum) XIII. 2002. Ed. Félix Rodríguez, La Colección Canónica Hispana, VI, 217-274. Madrid: CSIC.

Conc(ilium) Tolet(anum) XVI. 1862. Ed. Francisco Antonio González. PL, 84, 527-552. Paris.

Cons(ularia) Const(antinopolitana). 1892. Ed. Theodor Mommsen. MGH aa, 9/1, 205-247. Berlin: Weidmann.

Eutropius. 1913. De simil(itudine) carn(is) pecc(ati). Ed. Germain Morin. Études, textes, découvertes: contributions à la littérature et à I'histoire des douze premiers siècles. I, 107-150. Maredsous-Paris: Abbaye de Maredsous-Picard

Gregorius Ilib(erritanus). 1967. In Cant(icum) Cant(icorum). Ed. Johannes Fraipont. CCSL, 69, 169-210. Turnhout: Brepols Publishers.

Gregorius llib(erritanus). 1967. Tract(atus) Orig(enis) de libr(is) Sanct(arum) Script(urarum). Ed. Vincent Bulhart. CCSL, 69, 3-146. Turnhout: Brepols Publishers.

Gregorius Ilib(erritanus), Ps(eudo). 1967. De diu(ersis) gen(eribus) lepr(arum). Ed. Vincent Bulhart. CCSL, 69, 279-283. Turnhout: Brepols Publishers.

73 Augustinus, Serm., 279, 13 [c. 660]; 293B, 5 [p. 231].

74 Jean-Léon I'Africain 1980, 213. 
Gregorius Ilib(erritanus), Ps(eudo). 1967. De Salom(one). Ed. Vincent Bulhart. CCSL, 69, 253-259. Turnhout: Brepols Publishers.

Hieronymus. 1896. De uir(is) illustr(ibus). Ed. Ernest Cushing Richardson, Texte und Untersuchungen zur Geschichte der Altchristlichen Literatur 14/1a, 1-56. Leipzig: J.C. Hinrichs.

Hom(ilia) de sacril(egiis). 1896. Ed. Carl Paul Caspari. Eine Augustin fälschlich beilegte Homilia de sacrilegiis. Christiania: A. W. Brögger's Buchdruckerei.

Innocentius. 1845. Ep(istulae). Ed. Pierre Coustant. PL, 20, 485-493. Paris.

Isidorus. 1989. De eccl(esiasticis) off(iciis). Ed. Christopher M. Lawson. CCSL, 113. Turnhout: Brepols Publishers.

Licinianus Carth(aginis Nouae). 1948. Ep(istulae). Ed. José Madoz, Liciniano de Cartagena y sus cartas. Edición crítica y estudio histórico, 83-129. Madrid: Facultades de Teología y de Filosofía del Colegio Máximo de Oña.

Marcellinus et Faustinus. 1967. De confess(ione) uer(ae) fid(ei). Ed. Manlio Simonetti. CCSL, 69, 361-392. Turnhout: Brepols Publishers.

Marcus Diac(onus). 1930. Vit(a) Porph(yrii) Gaz(ensis). Ed. Henri Grégoire y Marc-Antoine Kugener, Marc le Diacre. Vie de Porphyre évêque de Gaza. Paris: Société «Les Belles Lettres».

Martinus Brac(arensis). 1950. De corr(ectione) rust(icorum). Ed. Claude W. Barlow, Martini Episcopi Bracarensis opera omnia, 183-203. New Haven: Yale University Press.

Pacianus. 2012. De paen(itentibus). Ed. Ángel Anglada. CCSL, 69B, 9-37. Turnhout: Brepols Publishers.

Priscillianus. 1889. Lib(er) apol(ogeticus). Ed. Georg Schepss. CSEL, 18 3-33. Wien: Tempsky.

Siricius. 1845. Ep(istulae). Ed. Pierre Coustant. PL, 13, 1131-1178. Paris.

Valerius Berg(idensis). 2006. Ord(o) querim(onie) pref(ati) discr(iminis). Ed. Manuel Cecilio Díaz y Díaz, Valerio del Bierzo. Su persona. Su obra, 246-276. León: Centro de Estudios e Investigación «San Isidoro".

Valerius Berg(idensis). 2006. Repl(icatio) serm(onum) a prim(a) conu(ersione). Ed. Manuel Cecilio Díaz y Díaz, Valerio del Bierzo. Su persona. Su obra, 280-310. León: Centro de Estudios e Investigación «San Isidoro».

Vit(a) Amand(i). 1910. Ed. Bruno Krusch. MGH srm, 5, 428-449. Hannover - Leipzig: Impensis Bibliopolii Hahniani.

Vit(a) Caes(arii Arelatensis). 2010. Ed. Germain Morin, Marie-José Delage y Marc Heijmans. SC, 536. Paris: Les Éditions du Cerf.

\section{BiBLIOgRAFíA}

Aherne, Consuelo María. 1949. Valerio of Bierzo. An Ascetic of the Late Visigothic Period. Washington D.C.: Catholic University of America.

Arbesmann, Rudolph. 1979. "The 'cervuli' and 'anniculae' in Caesarius of Arles». Traditio 35: 89-119.

Arce, Javier. 1971. "Conflictos entre paganismo y cristianismo en Hispania durante el S. IV». Príncipe de Viana 32: 245-255.

Arce, Javier. 1986. El último siglo de la España romana: 284-409. Madrid: Alianza.

Arce, Javier. 2005. Bárbaros y romanos en Hispania (400-507 A.D.). Madrid: Marcial Pons.

Arce, Javier. 2006. «Fana, templa, delubra destrui praecipimus: el final de los templos de la Hispania romana». Archivo Español de Arqueología 79: 115-124. https://doi.org/10.3989/aespa.2006.v79.6

Blázquez, José María. 1985. «Magia y religión entre los pueblos indígenas de la Hispania antigua». En Religión, superstición y magia en el mundo romano, 137-158. Cádiz: Universidad de Cádiz.

Blázquez, José María. 2010. «Relaciones entre Hispania y Galia en la Tarda Antigüedad. Siglos IV y V». En Hispania et Gallia: Dos provincias del Occidente Romano, ed. Lluís Pons, 177-191. Barcelona: Publicacions i Edicions de la Universitat de Barcelona.

Brown, Peter. 1995. Authority and the Sacred. Aspects of the Christianisation of the Roman World. Cambridge: Cambridge University Press.
Brown, Peter. 1997. El primer milenio de la cristiandad occidental. Barcelona: Crítica.

Brown, Peter. 2012. El mundo de la Antigüedad Tardía. Madrid: Gredos.

Cameron, Alan. 2011. The Last Pagans of Rome. Oxford: Oxford University Press.

Chadwick, Henry. 1978. Prisciliano de Ávila. Ocultismo y poderes carismáticos en la Iglesia primitiva. Madrid: Espasa-Calpe.

Crespo, Manuel José. 2009. Traducción y comentario filológico del Tractatus primus de Prisciliano de Ávila, intitulado Liber apologeticus. Tesis doctoral. Universidad Complutense de Madrid.

Crespo, Santos. 2004. «Conflicto religioso entre paganismo y cristianismo en la diócesis de Osma durante la Antigüedad Tardía hispana». Hispania Antiqua 28: 179-196.

Denk, Joseph. 1906. «Agniculam facere». Archiv für lateinische Lexikographie und Grammatik 14: 430-431.

Díaz, Pablo y Juana Torres. 2000. «Pervivencias paganas en el cristianismo hispano (siglos IV-VII)». En El cristianismo. Aspectos históricos de su origen y difusión en Hispania, ed. Juan Santos y Ramón Teja, 235-261. Vitoria: Universidad del País Vasco.

Fernández Ubiña, José. 1997. «El Libellus Precum y los conflictos religiosos en la Hispania de Teodosio». Florllib 8: 103-123.

Frighetto, Renan. 1999. «Um protótipo de pseudo-sacerdos na obra de Valério do Bierzo (Ordo querimoniae, 6)». Arys 2: 407-418.

García y Bellido, Antonio. 1967. "La latinización de España». Archivo Español de Arqueología 40: 3-29.

Geffcken, Johannes. 1929. Der Ausgang des griechisch-römischen Heidentums. Heidelberg: Carl Winters Universitätsbuchhandlung.

González Fernández, Rafael. 1995. "Cultura e ideología del siglo VI en las cartas de Liciniano de Cartagena». En Lengua e historia: homenaje al profesor Dr. D. Antonio Yelo Templado al cumplir 65 años, ed. Antonino González Blanco, 269-374. Murcia: Publicaciones de la Universidad de Murcia.

Hen, Yitzhak. 1995. Culture and Religion in Merovingian Gaul, A.D. 481-751. Leiden - New York - Köln: Brill.

Hillgarth, Joyce N. 1980. "Popular Religion in Visigothic Spain». En Visigothic Spain. New Approches, ed. Edward James, 3-60. Oxford: Clarendon Press.

Janvier, Yves. 1969. La législation du Bas-Empire Romain sur les édifices publics. Aix-en-Provence: La Pensée Universitaire.

Jean-Léon I'Africain. 1980. Description de l'Afrique, I. Paris: Librairie d'Amérique et d'Orient Adrien Maisonneuve.

Jiménez Sánchez, Juan Antonio. 2005. «La legislación civil y eclesiástica concerniente a las supersticiones y a las pervivencias idolátricas en la Hispania de los siglos VI-VII». Hispania Sacra LVII, 115: 47-78. https://doi.org/10.3989/hs.2005.v57.i115.117

Jiménez Sánchez, Juan Antonio. 2013. «Los magos en la Hispania tardorromana y visigoda». En Marginados sociales y religiosos en la Hispania tardorromana y visigoda, ed. Raúl González Salinero, 119-138. Madrid: Signifer Libros.

Jiménez Sánchez, Juan Antonio. 2015. «Clérigos y magia en Hispania durante la Antigüedad Tardía». Polis 27: 39-56.

Jiménez Sánchez, Juan Antonio. 2017a. «A Brief Catalogue of Superstitions in Chapter 16 of Martin of Braga's De correctione rusticorum». En Papers presented at the Seventeenth International Conference on Patristic Studies held in Oxford 2015, ed. Marcus Vinzent, 245-254. Studia Patristica, 97. Leuven - Paris - Bristol: Peeters Publishers.

Jiménez Sánchez, Juan Antonio. 2017b. «La cristianización de las calendas de enero en la Hispania tardoantigua». Latomus 76 (1): 162-184.

Lizzi Testa, Rita, ed. 2013. The Strange Death of Pagan Rome. Turnhout: Brepols Publishers.

MacMullen, Ramsay. 1997. Christianity and Paganism in the Fourth to Eighth Centuries. New Haven - London: Yale University Press.

Madoz, José. 1942. «Herencia literaria del presbítero Eutropio». Estudios eclesiásticos 16: 27-54. 
Madoz, José. 1948. Liciniano y Cartagena y sus cartas. Edición crítica y estudio histórico. Madrid: Facultades de Teología y de Filosofía del Colegio Máximo de Oña.

Mariner, Sebastián. 1976. «La difusión del cristianismo como factor de latinización». En Assimilation et résistance à la culture grécoromaine dans le monde ancien: travaux du Vle Congrès International d'Études Classiques (Madrid, Septembre 1974), ed. Dionis M. Pippidi, 273-274. Bucarest - Paris: Editura Academiei - Les Belles Lettres.

Markus, Robert Austin. 1990. The End of Ancient Christianity. Cambridge: Cambridge University Press.

Martínez, Víctor. 1972. «El paganismo en la España visigoda». Burgense 13 (2): 489-508.

Martínez Maza, Clelia, Francisco Javier Sanz Huesma y Pablo de la Cruz Díaz. 2007. Hispania tardoantigua y visigoda. Madrid: Istmo.

McKenna, Stephen. 1938. Paganism and Pagan Survivals in Spain up to the Fall of the Visigothic Kingdom. Washington D.C.: The Catholic University of America Press.

Menéndez Pelayo, Marcelino. 1880. Historia de los heterodoxos españoles. I. Madrid: Imprenta de F. Maroto e Hijos.

Meslin, Michel. 1970. La fête des Kalendes de janvier dans l'Empire romain. Étude d'un rituel de Nouvel An. Bruxelles: Latomus.

Morin, Germain. 1913. Études, textes, découvertes: contributions à la littérature et à l'histoire des douze premiers siècles. I. Maredsous - Paris: Abbaye de Maredsous - Picard.

Resta, Mario. 2014 «Il rapporto dei cristiani con la musica e la danza nella tarda antichità». Vetera Christianorum 51: 215-237.

Resta, Mario. 2015. "Saltationes sceleratissimorum. Music and Dance at Conciliar Canons and Papal Letters (IV-VII Sec.)». Synesis 7 (1): 110-123.

Rohlfs, Gerhard. 1948-1949. «Die anniculae bei Caesarius von Arles». Studia Neophilologica 21: 42-46.

Sanz, Rosa. 1995. "Hacia un nuevo planteamiento del conflicto paganismo-cristianismo en la Península Ibérica». Ilu. Revista de ciencias de las religiones 0: 237-248.Sanz, Rosa. 1998. "Adivinación y sociedad en la Hispania tardorromana y visigoda». En Estudios sobre la Antigüedad en homenaje al profesor Santiago Montero Díaz, 365389. Madrid: Universidad Complutense de Madrid.
Sanz, Rosa. 2003. Paganos, adivinos y magos. Análisis del cambio religioso en la Hispania Tardoantigua. Madrid: Universidad Complutense de Madrid.

Sanz, Rosa. 2007. «Aristocracias paganas en Hispania Tardía (s. V-VII)». Gerión 25, extra, 1: 443-480.

Sayas, Juan José. 1985. «Algunas consideraciones sobre la cristianización de los vascones». Príncipe de Viana 46: 35-56.

Schepss, Georg. 1889. Priscilliani quae supersunt. Wien: F. Tempsky.

Schmitt, Jean-Claude. 1992. Historia de la superstición. Barcelona: Crítica.

Segura, Santiago. 2001. Mil años de historia vasca a través de la literatura grecolatina: de Aníbal a Carlomagno. Bilbao: Universidad de Deusto.

Tronca, Donatella. 2017a. "Dancing in Ancient Christianity: Initial Research». En Texts, Practices, and Groups. Multidisciplinary Approaches to the History of Jesus' Followers in the First Two Centuries. First Annual Meeting of Bertinoro (2-5 October 2014), ed. Adriana Destro y Mauro Pesce, 433-448. Turnhout: Brepols. https://doi. org/10.1484/M.JAOC-EB.5.111715

Tronca, Donatella. 2017b. "L'uso della danza nella costruzione cristiana dell'alterità religiosa nella Tarda Antichità». Adamantius 23: 205-214.

Tronca, Donatella. 2019 «Spectacula turpitudinum. Christian Schemata of the Dancing Body». RIHA Journal 227. https://doi.org/10.11588/ riha.2019.2.70056

Vilella, Josep. 1997. «Un obispo-pastor de época teodosiana: Prisciliano». En Vescovi e pastori in epoca teodosiana, 503-530. Studia Ephemeridis Augustinianum, 58. Roma: Institutum patristicum Augustinianum.

Vilella, Josep. 2004. «La epistola 1 de Siricio: estudio prosopográfico de Himerio de Tarragona». Augustinianum 44 (2): 337-369.

Vilella, Josep. 2005. «Cánones pseudoiliberritanos y Código Teodosiano: la prohibición de los sacrificios paganos». Polis 17: 97-133.

Vilella, Josep. 2014. «The Pseudo-Iliberritan Canon Texts». Zeitschrift für antikes Christentum 18: 210-259. https://doi.org/10.1515/zac2014-0012

Vilella, Josep y Pere Enric Barreda. 2006. «¿Cánones del concilio de Elvira o cánones pseudoiliberritanos?». Augustinianum 46 (2): 285-373. 
